Dept. of Anatomy and Histology,

Fac. Vet. Med., Zagazig University,

Head of Dept. Prof. M.A. Ali.

\title{
SPERMATOGENIC PROCESS \\ IN CARBENDAZIMTREATED RATS
}

(With 1 Table \& 12 Figures)

\author{
by \\ A.A. ABUEL-ATTA
}

(Received at 20/6/1992)

\section{النسيه الطبد المنوك للفئران المعاملة

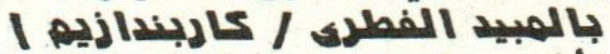

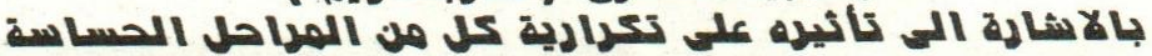

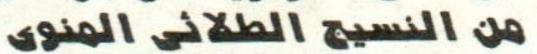

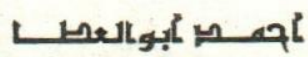

أجرى مذا البحث على ذكور فتران باكفة وسليمة طاهريا ، ظلت بالمعمل لمدة أسبوع

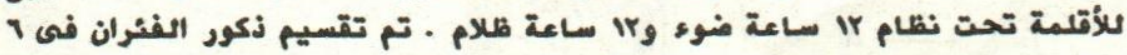

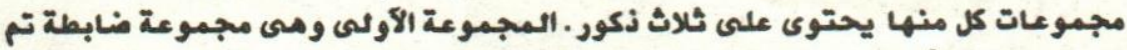

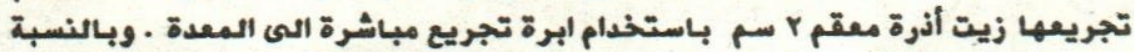

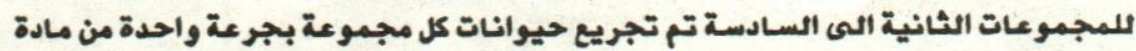

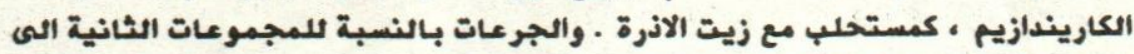

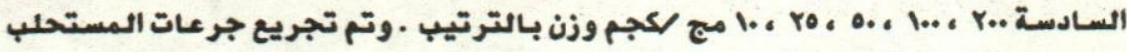

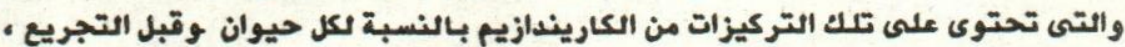

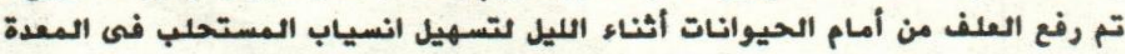

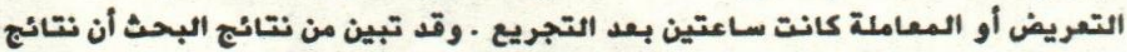

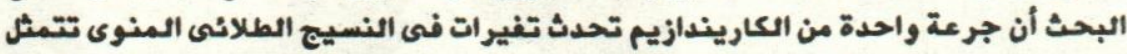

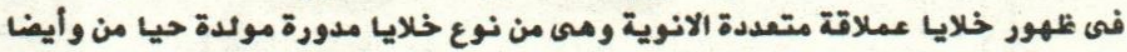

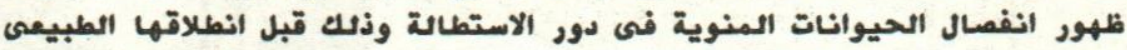
خصوصا فى مراحل .VII, XII-XII \& XIV. كما أن الاستجابة بتأثير مذه المادة

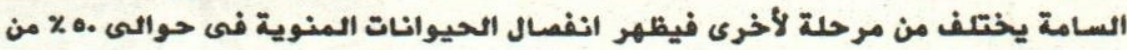

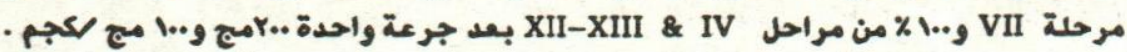

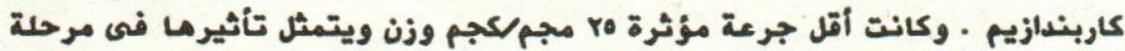

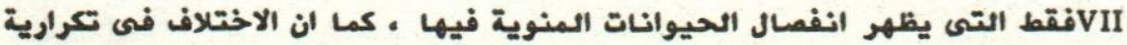




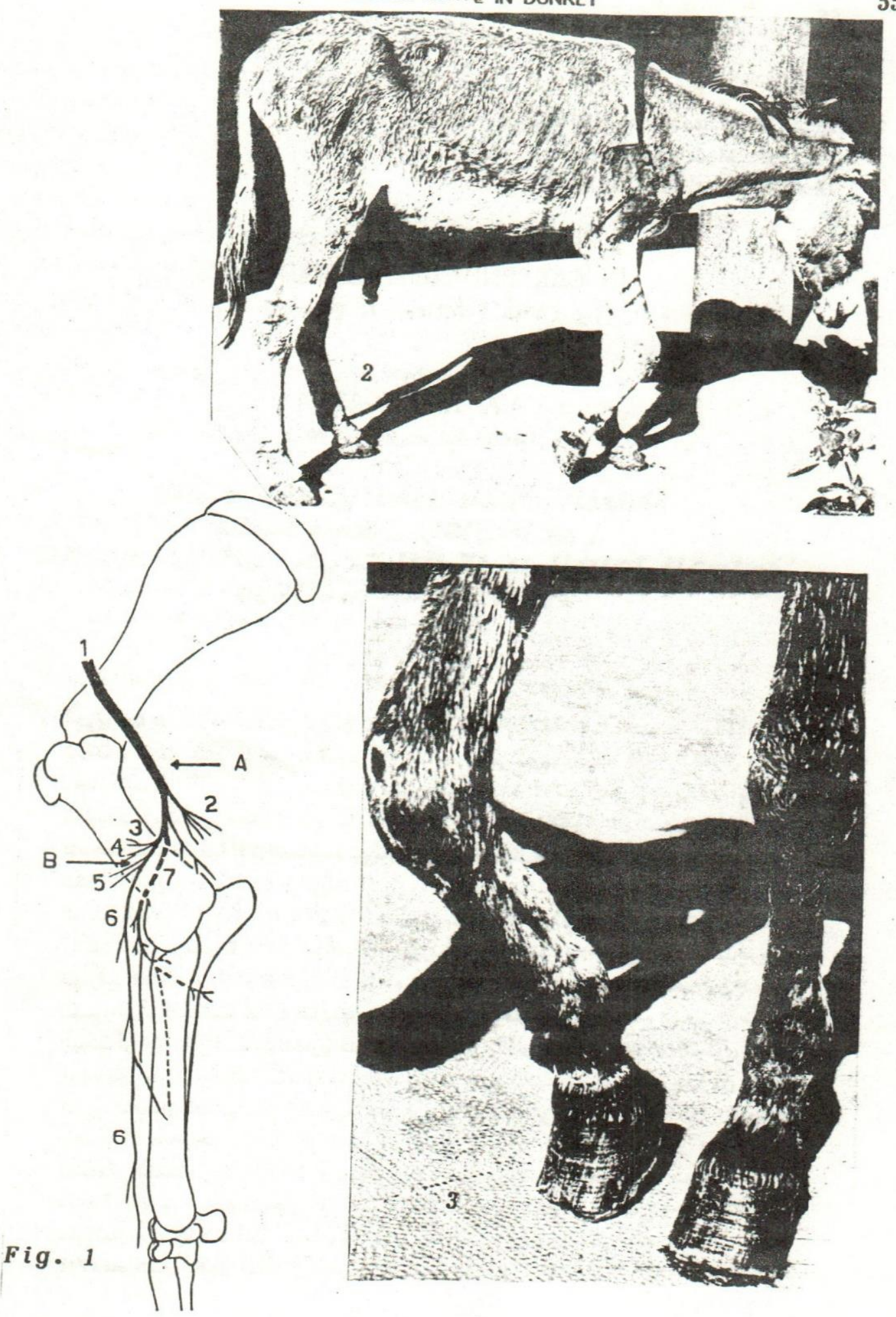

Assiut Yet. Med. J. Vol. 28. No. 55. October 1992. 


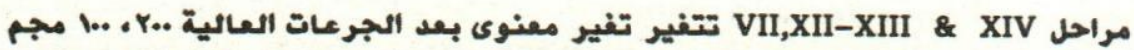

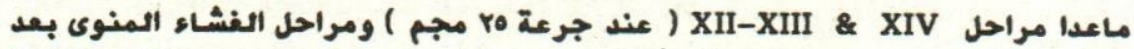

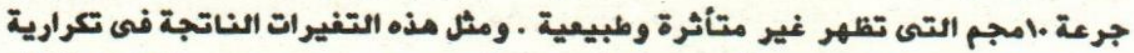

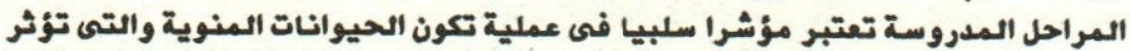

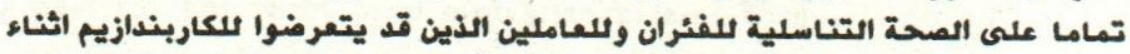

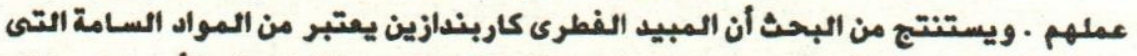

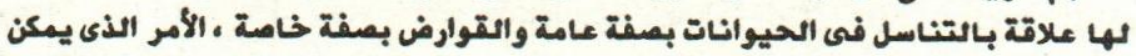

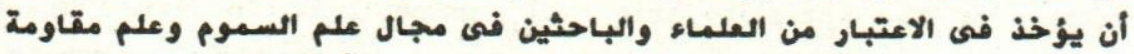

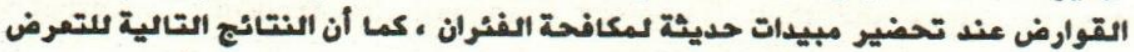

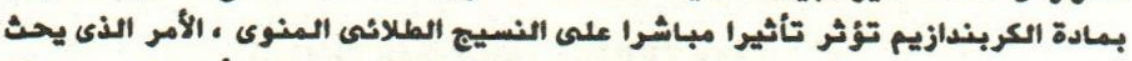

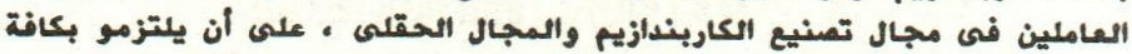
مقاييس الأمان وعدم التعرف له أثناء التعامل به وذلك لتجنب تأثثير الكاربندازيم السريع على خصية الانسان

\section{SUMMARY}

Six groups of adult male albino rats ( 3 animals each) were employed in this study. The 1st griyo (control) was given $2 \mathrm{ml}$ corn oil/rat. From the fungicide Carbendazim; 200, 100, 50, 25 and $10 \mathrm{mg} / \mathrm{Kg}$, emulsified in corn oil. A single dose of Carbendazim produced both dose- and stage- related changes, especially at certain stages (VII, XII-XIII \& XIV) of the seminiferous epithelium. These changes were represented as multinucleated giant round spermatids, and premature release (sloughing) of the elongated spermatids. The least effective dose $(25 \mathrm{mg} / \mathrm{Kg})$, caused sloughing of elongated spermatids only at stage VII. Meanwhile, at dose 200 and $100 \mathrm{mg}$, the sloughing appeared at about $50 \%$ of stage VII and extended to be $100 \%$ of stages XII-XIII \& XIV.

\section{INTRODUCTION}

The systemic fungicide Carbendazim (methyl 2-benzimidazole carbamate) is used to control a wide range of plant pathogens in vegetable fields. The Carbendazim effects were severe in adult male rats that received $400 \mathrm{mg} / \mathrm{Kg}$ body weight for 10 days, causing retardation of spermatogenesis in 7 of 12 adult male rats (CARTER et al., 1987). HESs et al. (1985) reported that a premature release of spermatids from the seminferous tubules occured as early as 2 hours after a single dose $400 \mathrm{mg}$ Carbendazim/ $\mathrm{Kg}$ body weight. 
Both carbendazim and Benomyl compounds are capable of disrupting spermatogenesis in adult rat (CARTER et al., 1987). However, the effect of Carbendazim on frequency of the stages of spermatogenic epithelium could not be traced in the availabe literature.

The objective of this investigation is to study the short-term ( 2 hours post-treatment) sequellae of Carbendazim-exposed spermatogenic epithelium in adult albino rats. This short exposure time was designed to recognize the changes of the spermatogenic cycle, as well as, to figure out the early sensitve stages and their frequency following the exposure to Carbendazim.

\section{MATERIAL and METHODS}

Adult male albino rats, 3 months old, were utilized for conduting this work. The animals spent a week for acclamatization in the laboratory (12 hours light/12 hours dark, fed barely and milk, and tap water ad libitum). The rats were divided into 6 groups ( 3 animals each). The 1st group received $2 \mathrm{ml}$ steralized corn oil only as a control group; the 2 nd to the 6 th griyo received 200, 100, 50, 25 and $10 \mathrm{mg}$ Carbendazim (Methyl 2-Benzimidazole Carbamate, MBC, provided by E.I. Du Pont de Nemours and Co., Wilmington, $\mathrm{DE}$ USA) per $\mathrm{Kg}$ body weight respectively. The $\mathrm{MBC}$ was emulsified in corn oil and given by oral gavage in volumes containing the designed MBC dose per rat. The rats were kept unfed for overnight. The post-treatment period was 2 hours. The rats were then aneasthetized using sodium pentabarbital, the testes were fixed by vascular perfusion (FORSSMANN et al., 1977), using Bouin's fixative. Paraffin sections were stained with Hematoxylin and Eosin (DRURY and WALLINGTON, 1980), and also with Periodic Acid Schiff technique, counterstained with Hematoxylin to help in recognizing the stages of spermatogenesis (HESS, 1990). The number of each stage was counted per one hundred seminfierous tubules from each treated testis and the same stages were counted parallely in testes of the conrol rats. The frequency (\%) of each of the sensitive stages in MBC-treated rats was studied in comparison with the control testes. Statistical Analysis System "SAS" (1987) was adopted to interpretate the data.

\section{RESULTS}

Comparing the seminiferous tubules of the control with those of the Carbendazim-treated rats, the sensitive and the early affected cell associations 
(stages), which showed a detectable changes, were stages VII, XII-XIII and $X I V$, except in the $10 \mathrm{mg} \mathrm{MBC}$-treated testes which showed normal spermatogenic epithelial lining similar to those of the control (corn oil-treated) testes (Fig. 1 and 2).

Corn oil (control) testes: Stage VII: It was characterized by the presence of two spermatids types: the elongated step 19 spermatids, aligned along the luminal border of the spermatogenic epithelium, followed by the rounded step 7 spermatids with centrally located rounded nuclei and an acrosome covering about $1 / 3$ of their basal surfaces. Stage VIII, showing residual bodies, which were present beneath step 19 spermatids (Fig. 2).

Stage XII-XIII: They were characterized by absence of the rounded spermatids. The elongated spermatids had blunt acrosomes, with long and narrow slightly bent heads (Fig. 3 and 4). Spermatogonial mitotic figures were seen at stage XII only on the basement membrane (Fig. 3).

Stage XIV: It was defined by the presence of numerous divisions, together with step 14 spermatids. Transition between stage XIII and XIV was present (Fig. 5 and 6).

MBC-treated testes:

Carbendazim (MBC) induced short-term sequellae amoung the spermatogenic epithelium at doses of $200,100,50 \& 25 \mathrm{mg} \mathrm{MBC} / \mathrm{Kg}$ body weight. The $25 \mathrm{MBC}$ dose was the least effective dose, while the $10 \mathrm{mg} \mathrm{MBC}$ dose didn't show any detectable change and the spermatogenic epithelium was unaffected and appeared normal.

The MBC-induced changes were manifested as multinucleated giant round spermatids, premature release (sloughing) of elongated spermatids, and exfoliation of some round spermatids. These changes were mainly detectable at certain cell associations (stages); VII, XII-XIII \& XIV of the spermatogenic epithelium (Fig. 7 to 12).

of particular interest, the MBC-induced changes appeared variable among the affected stages. The frequencies (\%) of the sensitive (affected) stages VII, XII-XIII \& XIV (showing sloughing or not) in testes of control and MBC-exposed rats were caliculated, the least square means and standard errors of these frequencies were shown in table (1). At $200 \& 100 \mathrm{mg} \mathrm{MBC}$ doses, about $50 \%$ or less of stage VII and $100 \%$ of stages XII-XII \& XIV exhibited sloughed elongated spermatids. At $50 \mathrm{mg} \mathrm{MBC}$ dose, more than $50 \%$ of stage VII, less than $50 \%$ of XII-XIII, and about $50 \%$ of stage XIV possessed 
sloughed spermatids. Later on, at $25 \mathrm{mg} \mathrm{MBC}$ dose, despite less than $50 \%$ of stage VII showed sloughed spermatids, stages XII-XIII and XIV didn't show any detectable sioughing. The frequency of stages XII-XIII (showing sloughed spermatids in rat subjected to 200 or $100 \mathrm{mg} \mathrm{MBC}$ dose), was significantly increased (Table 1).

\section{DISCUSSION}

The present study revealed that a single dose of Carbendazim produced dose- and stage- related effects $(200,100,50 \& 25 \mathrm{mg} \mathrm{MBC} / \mathrm{Kg}$ body weight) on the spermatogenic epithelium especially at certain stages; VII, XII-XIII \& XIV. The MBC-induced changes of these stages were disorganization of their epithelia, appearance of multinucleated giant round spermatids, and premature release (sloughing) of the elongated spermatids. The least effective MBC-dose was $25 \mathrm{mg} / \mathrm{Kg}$ body weight. Of particular interest, such damage resulted in a dramatic alterations in the frequency of the sensitive stages of the spermatogenic cycle.

Similar sloughing was reported as early as 2 hours after a single dose of $400 \mathrm{mg} \mathrm{MBC} / \mathrm{Kg}$ body weight (HESS et al., 1985). Meanwhile, $400 \mathrm{mg}$ Benomyl or Carbendazim/ $\mathrm{Kg}$ body weight for 10 successive days, followed by 2 weeks post-treatment period, induced disruption of all stages of spermatogenesis (CARTER and LASKEY, 1982), since MBC is identical to the metabolite of Benomyl (GARDINER et al., 1974). The least effective MBC dose of the current study, was $25 \mathrm{mg} / \mathrm{Kg}$ body weight. Benomyl has the same least effective dose, as announced by HESS et al. (1991), who added that sloughing was found primarily in stages VII at lower dosages, and extended to be in all stages at higher Benomyl dosages except for stages VIII-XI.

The sloughing of elongated spermatids in our work is similar to that induced after a single dose of $400 \mathrm{mg} \mathrm{MBC} / \mathrm{Kg}$ (HESS et al., 1985), that could be attributed to the removal of barely overnight before gavage of MBC. Thus, the amount of food inside the stomach could possess a dramatic effect on the testicular response.

The current study revealed a premature release (sloughing) of elongated spermatids resulting 2 hours after MBC exposure, which seems to be dose- or/and stage-dependant response. FAWCETT et al. (1971), mentioned that acrosome formation, nuclear condensation and elongation of spermatids take place during spermatogenesis. Moreover, spermatids elongation is dependant upon normal microtubulin formation (CARTER and LASKEY, 1982), 
which has been inhibited by Carbendazim (DAVIDSE and FLACH, 1977). Concurrently, sloughing of elongated spermatids after MBC exposure, could be due to disruption of Sertoli cell apices, which may be a result to impaired structure and function of the microtubules, especially at the sensitive stages; VII, XII-XIII \& XIV of the seminiferous epithelium.

The microtubule inhibitor such as MBC may interfere during the early stages of spermatogenesis (DAVIDSE and FACH, 1977). In addition, development and maintenance of the shape of spermatozoa during the final stages of spermiogenesis, are dependant upon microtubules (FAWCETT et al., 1971). Similar findings were concluded too, since the MBC-sensitive stages were VII, XII-XIII and XIV (which present early in the cycle of the spermatogenic epithelium), and stage VII (late of the cycle), because the cycle of spermatogenesis begins with a spermatogonial mitosis at stage IX and ends with a release of spermatozoa at the end of stage VII (ROOSEN-RUNGE and GIESEL, 1950).

The frequency of a particular stage in a cross section of testis is proportional to the percent of time occupied by that stage (CLERMONT and HARVEY, 1965). The amount of time per cells of each stage is constant (COUROT et al., 1970). From the present results, the frequency in table 1 per each studied stage, was significantly changed, particularly at dose 200,100 $\mathrm{mg} \mathrm{MBC}$, an indication of a disturbance in the kinetics of spermatogenesis.

In conclusion, the MBC-induced changes could be considered from the toxicologists during the preparation and formulation of a new effective rodenticide, containing Carbendazim, which had the potential to affect the reproductive health of rodents. Moreover, the handling of such toxic chemical in factories or fields must be faced with the highest safety precutions, in order to avoid the MBC-induced testicular response in human may exposed to such reproductive toxin by hazards.

\section{REFERENCES}

Carter, S.D; Hess, R.A. and Laskey, J.W. (1987): The fungicide methy 2-benzimidazole carbamate causes infertility in male Sprague-Dawely rats. Biol. Reprod. 37: 709-717.

Carter, S.D. and Laskey, J.W. (1982): Effect of benomyl on reproduction in male rat. Toxicol. Letters, 11: 87-94. 
Clermont, Y. and Harvey, S.C. (1965): Duration of the cycle of the seminiferous epithelium of normal, hypophysectomized and hypophysectomized hormone treated albino rats. Encocrinology 76: 80-89.

Courot, M.; Hochereau-ce Reviers, M.T. and Ortavant, R. (1970): Spermatogenesis. In: Johonson A.D.; Gomes, W.R.; Vandemark, N.L., eds. The testis; Vol. L. New York: Academic Press, 339-432.

Davidse, L.C.; Flach, W. (1977): Differential binding of methyl benzimidazol-2-yl carbamate to fungal tubulin as a mechanism of resictance to fungal tubulin as a mechanism of resistance to this antimitotic agent in mutant strains of Aspergillus nidulans. J. Cell. Biol. 72: 174.

Drury, R.A.B. and Wallington, E.A. (1980): Carlton's histological technigue. 4th Ed. Oxford University Press. New York, Toronto.

Fawcett, D.W. ; Anderson, W.R. and phillips, D.M. (1971): Morphogenetic factors influencing the shape of the sperm head. Develop. Biol., 26: 220.

Forssmann, W.G.; Ito, S.; Weihe, E.; Aoki, A. and Fawcett, D.W. (1977): An improved perfusion fixation method for the testis. Anat. Rec. 188: 307-314.

Gardiner, J.A.; Kirkiand, J.J.; Klopping, H.I. and Sherman, I1. (1974): Fate of benomyl in aximaie. J. Agric. Food Chem., 22: 419-427.

Hess, R.A. (1990): Quantitative characteristics of the stages and transitions in the cycle of the seminiferous epithelium: Light microscopic observations of perfused-fixed and plastic-embedded testes. Biology of Reproduction 43: 525-542.

Hess, R.A.; Linder, R. and Strader, L. (1985): Sloughing of spermatids and residual cytoplasm caused epididymal occlusion and testicular swelling: an acute study of carbendazim and benomyl, benzimidazcle derivatives. $J$. Andral (Abst.) 6: 58.

Hess, R.A.; Moore, B.J.; Forrer, J.; Linder, R.e. and Ahmed Awad Abuel-Atta (1991): The fungicide benomyl (methyl 1-(butylcarbamoyl)-2-bezimidazolecar bamate) causes testicular dysfunction by inducing the sloughing of germ celis and occlusion of efferent ductules. Fundamental and Applied Toxicology 17: 733-745.

Leblond, C.P. and Clermont, Y. (1952): Definition of the stages of the cycle of the seminifercus epitheium in the rat. Ann. NY Acad. Sci., 55: 548-573.

Rcoeen-Runge, E.C. and Giescl, L.O. (1950): Quantitative studies on spermatogenesis in the albino rat. Am. J. snat., 78: 1-22. 
Russel, L.D.; Ettlin, R.A.; SinhaHikim, A.P. and Cleg, R.D. (1990): Histological and histopathological evaluation of the testis. Cache River Press, USA. SAS Institute Inc. (1987): SAS user's guide. Statistics. Cary, North Cartolina.

\section{LEGENDS}

Fig. 1: Seminiferous tubules of control rats. PAS-Haematoylin stain, Obj: $\mathrm{X} 20$,
Oc.: $\mathrm{X} 10$.

Fig. 2: Seminiferous tubules of control rats, showing stages VII and VIII. PAS-Haematoxylin stain, Obj: X40, Oc.:x10.

Fig. 3: Seminiferous tubules of control rats, showing mitotic activity (arrow) at the spermatogonial cells. PAS-Haematoxylin stain, Obj: X40, Oc. X10.

Fig. 4: Seminiferous tubules of control rats, showing stages XII and XIII. PAS-Haematoxylin stain, Obj: X40, Oc.: x10.

Fig. 5: Seminiferous tubules of control rats, showing transition between stage XIII and stage XIV. PAS-Haematoxylin stain, Obj: $X 40$, Oc.: $x 10$.

Fig. 6: Seminiferous tubules of control rats, showing stage XIV. PAS-Haematoxylin stain. Obj: X40, Oc.: x10.

Fig. 7: Seminiferous tubules of $25 \mathrm{mg}$ MBC-treated rat, showing multinucleated giant rounded spermatids. Haematoxylin and Eosin stain. Obj.: X40, Oc.: x10.

Fig. 8: Seminiferous tubules of $25 \mathrm{mg}$ MBC-treated rat, showing stage VII with sloughed elongated spermatids (S) and stage VII which appears normal (N). PAS-Haematoxylin stain. Obj: X40, Oc.: X10.

Fig. 9: Seminiferous tubules of $50 \mathrm{mg}$ MBC-treated rat, showing sloughing of elongated spermatids within the lumina of the tubules. PAS-Haematoxylin stain. Obj: $\mathrm{X} 20$, Oc.: $\times 10$.

Fig. 10: Seminiferous tubules of $100 \mathrm{mg}$ MBC-treated rat, showing sloughed elongated spermatids at stage XII and stage XIV. Obj.: X40, Oc.: x10.

Fig. 11: Seminiferous tubules of $100 \mathrm{mg}$ MBC-treated rat, showing sloughed elongated spermatids at a transition between stage XIII and stage XIV. PAS-Haematoxylin stain. Obj: $\mathrm{X} 40$, Oc.: $x 10$.

Fig. 12: Seminiferous tubules of $200 \mathrm{mg} \mathrm{MBC}$-treated rat, showing sloughed spermatids within the lumina of the tubules. PAS-Haematoxylin stain, Obj: X20, Oc.: x10. 


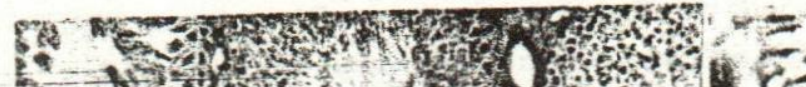

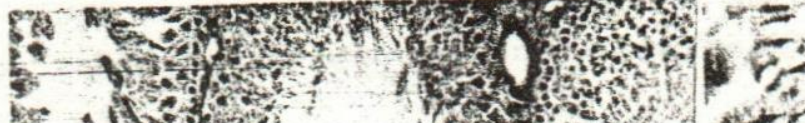

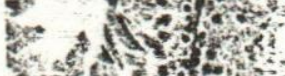

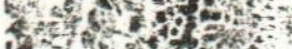

P.

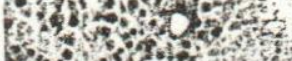

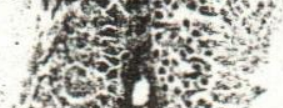

क sin

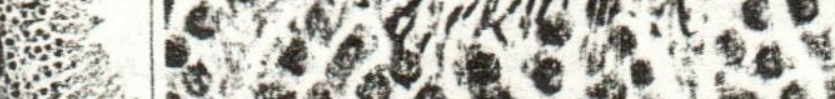

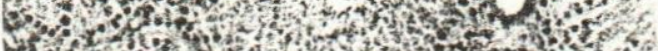

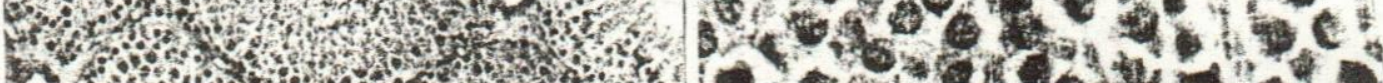

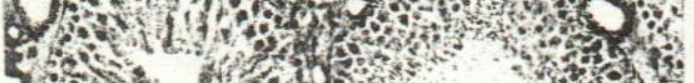

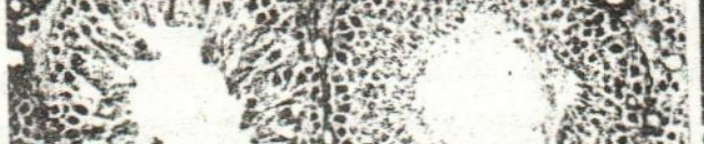
13t.

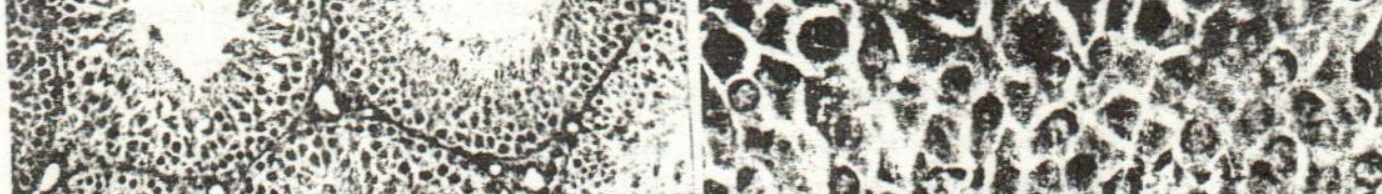

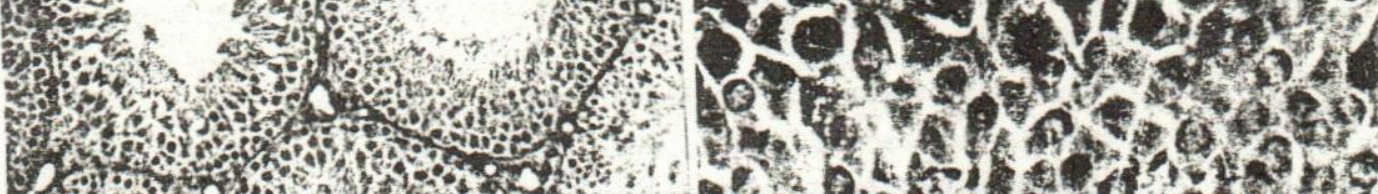

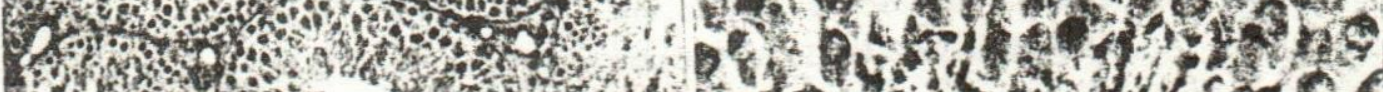

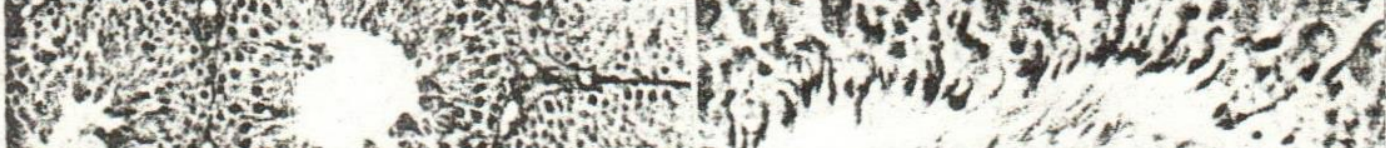

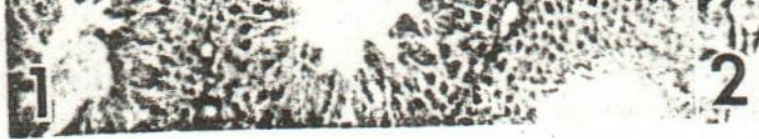
- prays

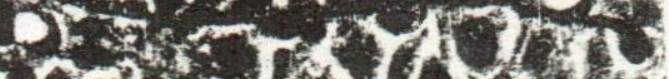

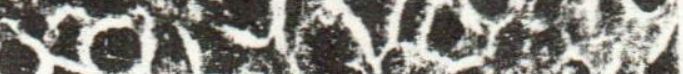

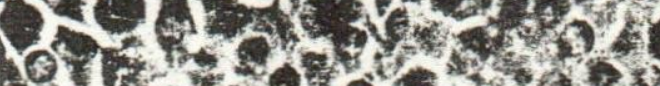
I.

s.

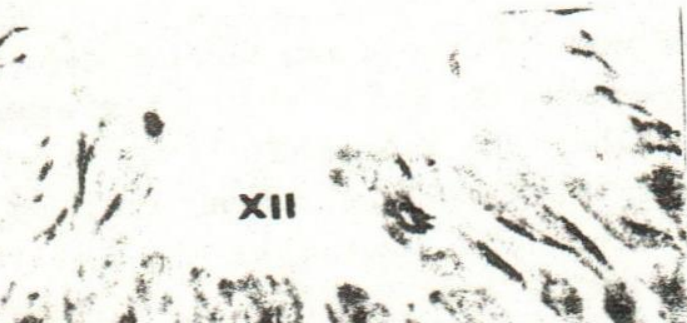

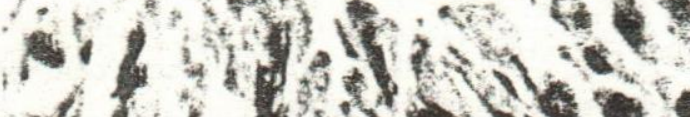
19.

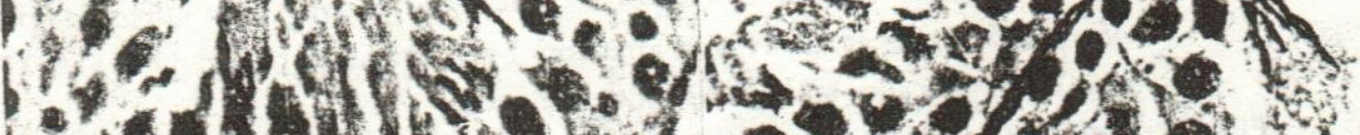

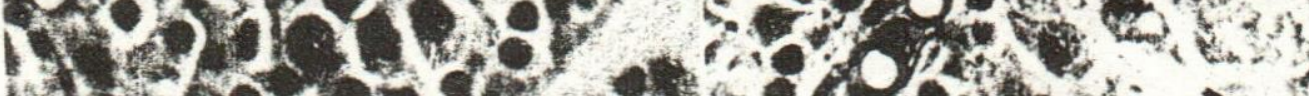

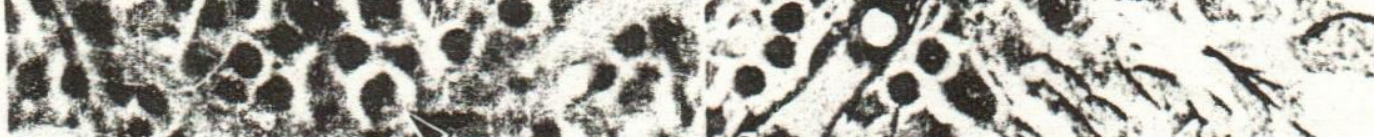

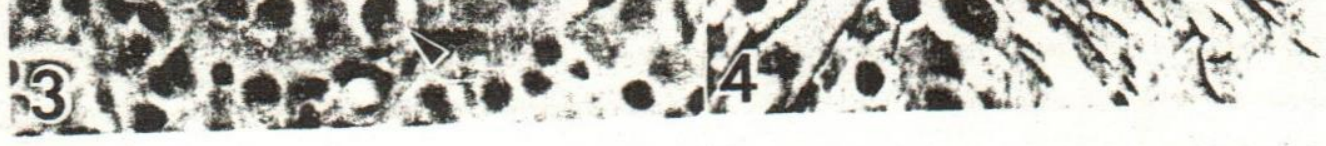



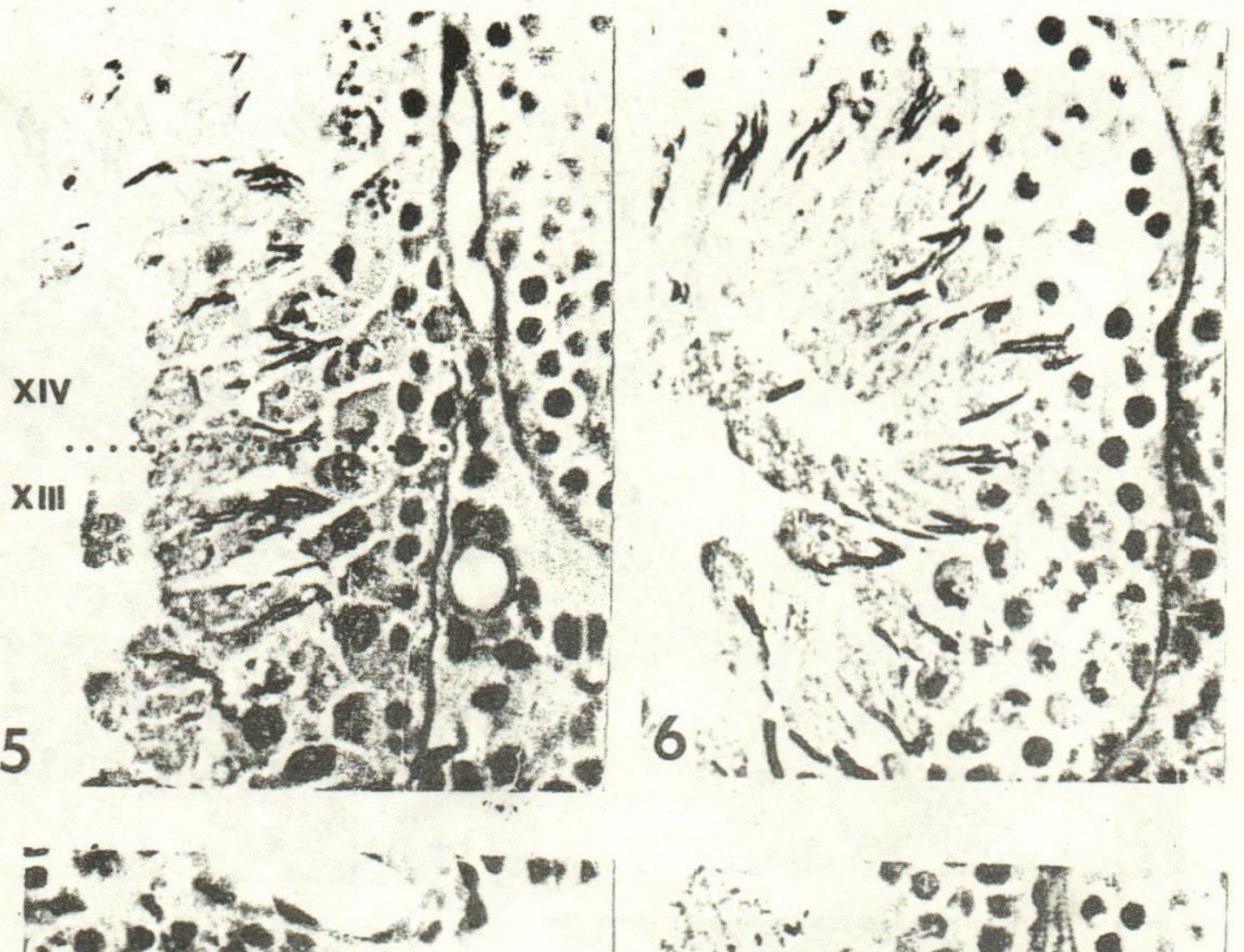

1.58 (2)

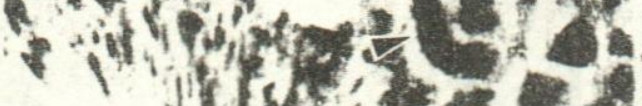
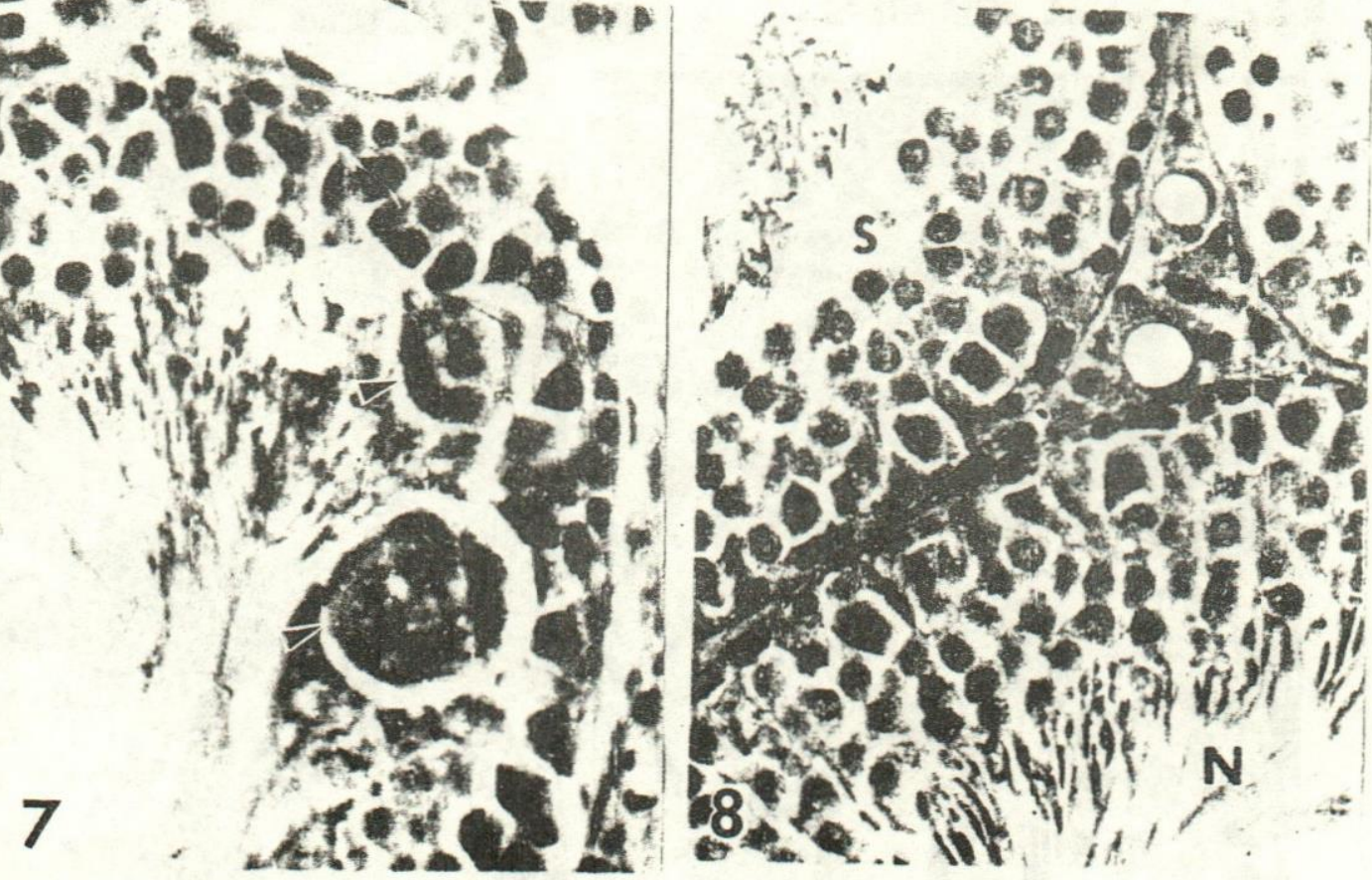

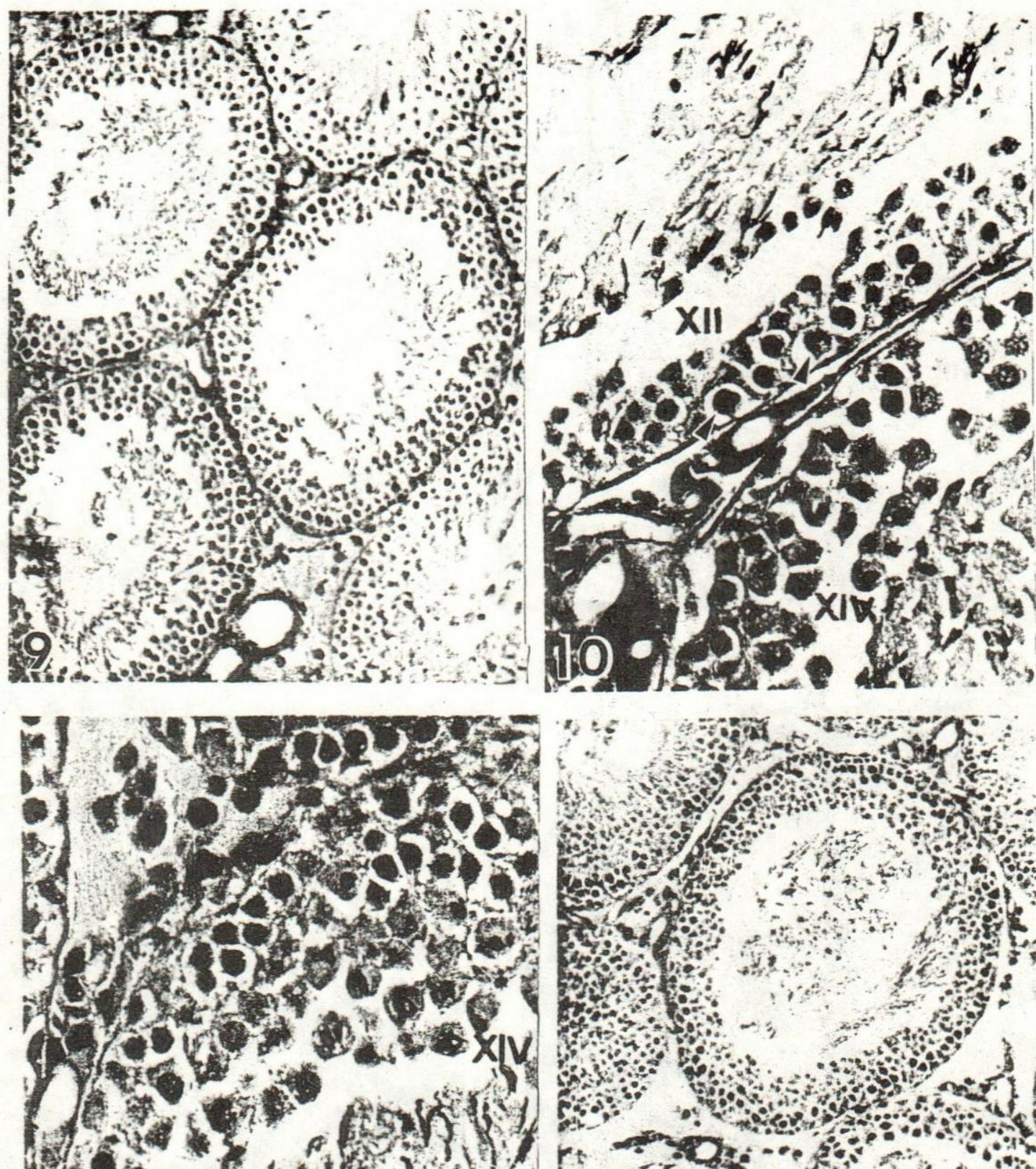

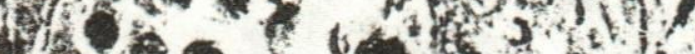

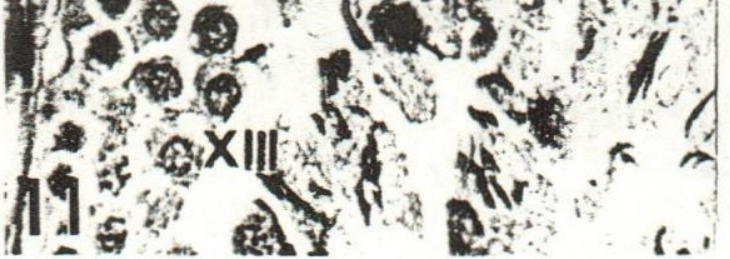

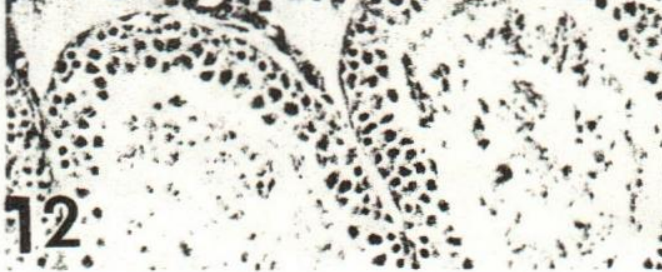

